\title{
Preparation and characterization of novel $\mathrm{PA} 6 / \mathrm{SiO}_{2}$ composite microsphere applied for selective laser sintering
}

\author{
G. X. Wang ${ }^{*}$, P. Liu, W. Zhang, Zh. Ch. Zhen, X. W. Wang, B. Lu, P. L. Wang, J. H Ji
}

National Engineering Research Center of Engineering Plastics, Technical Institute of Physics and Chemistry, The Chinese Academy of Sciences, 100190 Beijing, P. R. China

Received 19 June 2017; accepted in revised form 21 August 2017

\begin{abstract}
The high cost and less variety of raw materials has greatly restricted the wide application of selective laser sintering (SLS) technology. In order to make the material cheaper and more diverse, PA6 is the most preferable material. In this work, a new $\mathrm{PA} 6 / \mathrm{SiO}_{2}$ composite microsphere used for SLS was designed and fabricated. To construct the material, PA6 porous microspheres with diameters of $20-80 \mu \mathrm{m}$ and a certain pore volume were firstly prepared by the dissolution precipitation method. Then, $\mathrm{SiO}_{2}$ was generated in situ in the PA6 porous microsphere framework, thus achieving a special structured $\mathrm{PA} 6 / \mathrm{SiO}_{2}$ composite microsphere. These microspheres with much well dispersed $\mathrm{SiO}_{2}$ in $\mathrm{PA} 6$ matrices formed a powder with high bulk density and good electron conductivity. The particle size and weight fraction of the two components can be well controlled by adjusting the experimental conditions. Differential scanning calorimetry (DSC) data showed that the composite powder had a larger sintering window, which would be beneficial for SLS processing. The introduction of $\mathrm{SiO}_{2}$ reduced the rate of water absorption in the composite powder, which could improve the accuracy of SLS forming. This work has certain significance as a reference for the design and development of SLS polymer-based composite materials.
\end{abstract}

Keywords: polymer composites, PA6 microspheres, selective laser sintering, preparation and characterization

\section{Introduction}

SLS is one of the most developed and widely used $3 \mathrm{D}$ printing technologies $[1,2]$. The laser sintering process allows complex 3D objects to be built by selectively fusing together successive layers of powdered material. Theoretically, the wide range of material choices is a major advantage of SLS technology, because any powder that can be bonded after heating can be applied in SLS technology, but in practical applications, powder materials that can be successfully used are scarce [3-8]. The main reason for this scarcity is that SLS technology requires high-performance powder materials. For example, in order to create molded parts with good dimensional accuracy and mechanical strength, the resin material used to prepare the powder should have an appropriate melting point, high thermal stability, small shrinkage rate, and suitable melt viscosity. Furthermore, the prepared powder particles should have approximately spherical structures with diameters of $20-80 \mu \mathrm{m}$, permitting greater powder fluidity and higher bulk density $[9,10]$.

Polyamide-12 (PA12)-based powder is one of the only materials used for SLS technology because it has good dimensional stability, a low melting point, easy processing, and a small shrinkage rate [11-16]. However, the cost of PA12 powder is very high; even simple sintered parts with volumes of $10 \mathrm{~cm}^{3}$ cost thousands of dollars for the raw material alone. In addition, the use of PA12 powders often creates unsatisfactory mechanical properties. The thermal stability of the material is decreased under strong irradiation with UV or long-term UV exposure, which makes both powder and sintered products prone to 
yellowing $[17,18]$. Therefore, the development of new high-performance and low-cost polymer powders is urgent.

PA6 is the most widely and successfully used engineering polymer, with a price of only $1 / 5$ of that of PA12. PA6 has a higher melting point, thermal deformation temperature, and thermal decomposition temperature than PA12 does [19-21]. The modification technology for PA6 is also more mature. The excellent bending strength, tensile strength, and notched impact strength allow widespread use of PA6 in personalized consumer goods, as well as the automotive, aerospace, and medical industries, among other fields. If PA6 could be used in SLS technology, not only would the material cost be effectively reduced, but also the application of SLS would be broadened into the fields of customization, aerospace, automotive, construction, and medicine. Nevertheless, the commercialization of PA6 powder material has not yet succeeded. The greatest obstacle is determining the preparation technique for high-quality PA6 microspheres. In addition to this, the high water absorption rate of the hydrophilic amide group in the PA6 polymer chain is a problem. For direct application in SLS processing, the water absorption rate greatly influences the powder in the molding process, as well as the thermal stability, size stability, and mechanical strength of the sintered product. Therefore, the preparation of SLS microsphere structures with the required 20-100 $\mu \mathrm{m}$ diameter and the reduction of the water absorption rate are the two crucial problems to solve before PA6 powder can be applied in SLS. Methods for synthesizing PA polymeric microspheres are seldom researched in recent documents [22-25]. Hou and Lobuglio [22] prepared uniform spheres of PA6/PA12 polymers from a $1 \mathrm{wt} \%$ theta solvent when cooling the solution rapidly to a point below the theta temperature. Li et al. [23] obtained high-crystallinity PA6 microspheres by a slow solvent evaporation method from a high-concentration PA6/formic acid solution. In the literature, the maximum size of PA6 microspheres is a few micrometers, and the preparation of PA6 microspheres with sizes of several tens of micrometers and applicability in SLS technology is rarely reported.

PA6 is a semi-crystalline material. The rate of water absorption therefore depends on the polar amide, amino, and carboxyl groups on the polymer chains in the amorphous regions [26]. Thus, the water absorption of PA6 can be reduced by improving the degree of crystallinity to reduce the water absorption probability of the amorphous region or adding nonpolar filler modification to inhibit water penetration. $\mathrm{SiO}_{2}$ is cheap, easily obtained, and the most commonly used material for the modification of PA6 [27]. The silicon hydroxyl on $\mathrm{SiO}_{2}$ and amide groups on the PA6 polymer chain can form stable intermolecular interactions, thereby significantly improving the material hydrophobicity, thermal stability, and mechanical properties [28, 29]. The sol-gel approach, used to synthesize PA6 nanomaterials has received considerable interest in recent decades. However, most previous studies investigated PA6 films or sheets with nanoscale $\mathrm{SiO}_{2}$ mainly distributed on the surface of the PA6 matrices at low-volume loading [30-33]. The preparation of $\mathrm{PA} 6 / \mathrm{SiO}_{2}$ composites, especially microspheres with high dispersion and high loading weight, is more challenging and rarely reported.

Particular interest in developing new materials used for SLS, a new special structured $\mathrm{PA} 6 / \mathrm{SiO}_{2}$ was designed and fabricated in this study. To construct the material, PA6 porous microspheres with diameters of $20-80 \mu \mathrm{m}$ and a certain pore volume were prepared by the dissolution precipitation method. High content of $\mathrm{SiO}_{2}$ was generated and well dispersed in situ in the PA6 porous microsphere framework, thus achieving $\mathrm{PA} 6 / \mathrm{SiO}_{2}$ composite microsphere with the mean diameter of $20-80 \mu \mathrm{m}$ (Figure 1). By introducing the $\mathrm{SiO}_{2}$ particles, the bulk density, electron conductivity, and laser sintering window of the PA6 composite powder were significantly improved. More importantly, the increased crystallinity and surface roughness of the PA6 matrix consequently decreased the water absorption rate of $\mathrm{PA} 6 / \mathrm{SiO}_{2}$ composite powder.

\section{Experimental}

\subsection{Materials}

PA6 pellets with a type of B30S were purchased from BASF. Polyvinylpyrrolidone (PVP) with the molecular weight of $M_{\mathrm{w}}=40000 \mathrm{~g} / \mathrm{mol}$ (PVPK30) was purchased from Guang Zhou Xilong Chemical Reagent Co., China. Formic acid and tetraethoxysilane (TEOS) were purchased from Sigma-Aldrich. The polymers in this study were all commercial products and used without further purification or fractionation. Therefore, the molecular weight and chain length distributions can be assumed as broad. 

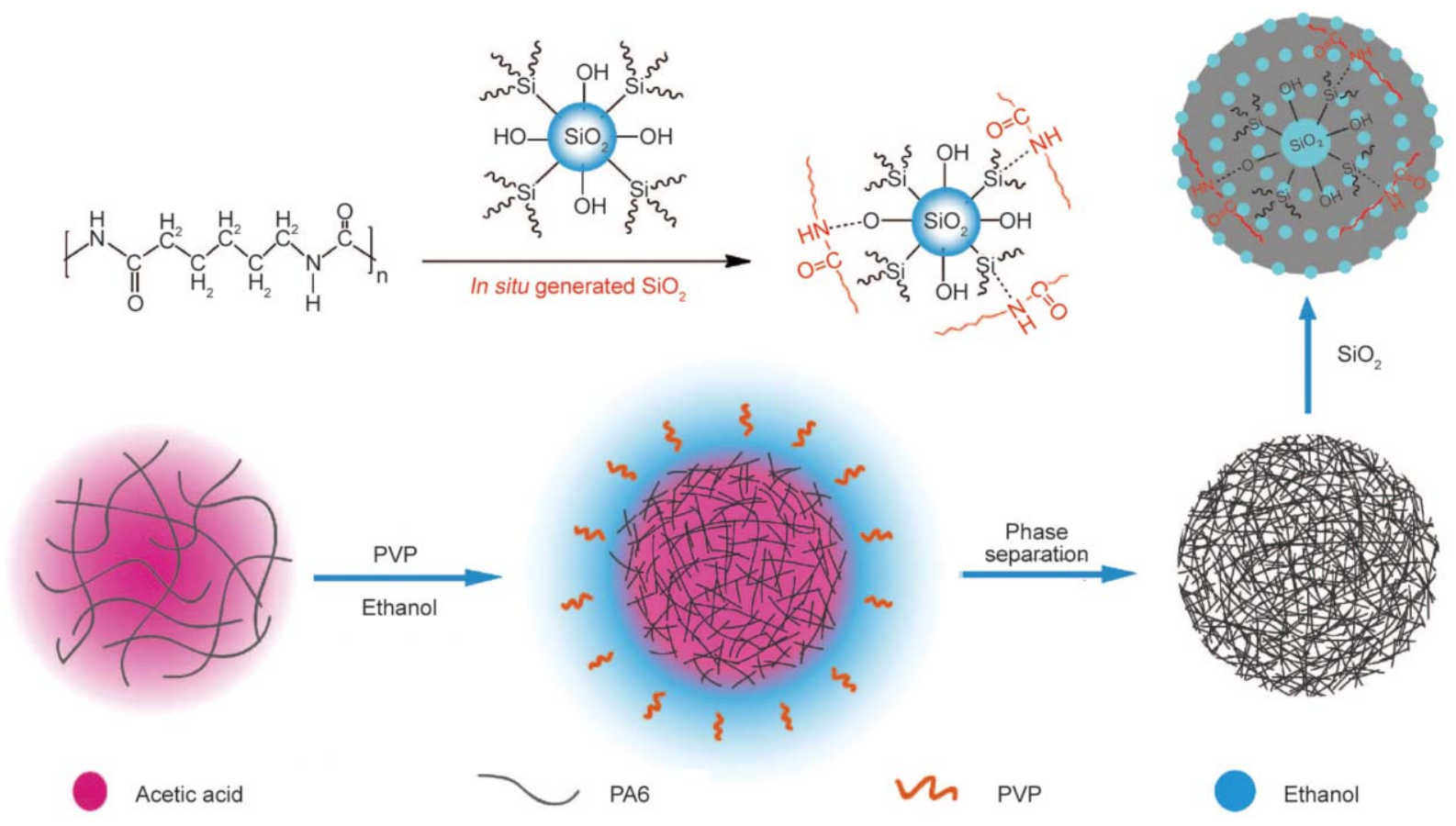

Figure 1. Schematic of the preparation of $\mathrm{PA} 6 / \mathrm{SiO}_{2}$ composite microspheres

\subsection{Instruments}

The surface morphologies of the PA6 porous microspheres and the $\mathrm{PA} 6 / \mathrm{SiO}_{2}$ composites were examined by using a Hitachi S-4800 scanning electron microscope (SEM). The cross-sections of the PA6 porous microspheres and $\mathrm{PA} 6 / \mathrm{SiO}_{2}$ composite microspheres were detected by using a 3-in-1 multibeam ion microscope Orion NanoFab from Carl Zeiss Company. This system covers the complete range of micromachining to nanomachining applications using gallium, neon and helium ion beams integrated in a single instrument, as well as high resolution imaging capability in the same instrument. The optional gallium focused ion beam (FIB) column were used to cut off the target PA6 microparticles by removing one half of the massive material, then high resolution microscope system was used to characterized the other half of the particle. The bulk density was determined by measuring the volume of a known mass of sample powder that was passed through a screen into a graduated cylinder, according to the USP32 (616) standard (Method I). A dry $250 \mathrm{~mL}$ cylinder was used to test approximately $100 \mathrm{~g}$ of sample material; the measurement was repeated three times to obtain an average value. The pores volume and other pores properties were detected by using mercury porosimetry Pore Master GT 60.

The thermal stability and $\mathrm{SiO}_{2}$ contents in the PA6 composite microspheres were determined using thermogravimetric analysis (TGA) with an SDTA 851
Thermobalance apparatus. The samples were heated to $800^{\circ} \mathrm{C}$ with a heating rate of $10^{\circ} \mathrm{C} / \mathrm{min}$ for $90 \mathrm{~min}$ under a nitrogen atmosphere. The wt $\%$ of $\mathrm{SiO}_{2}$ was calculated using curve plateaus. The thermal behaviors of the materials were characterized by differential scanning calorimetry (DSC) experiments. The first running of melt and crystalize behavior were detected using a Mettler-DSC1 at a heating rate of $10^{\circ} \mathrm{C} / \mathrm{min}$ and a cooling rate of $-10^{\circ} \mathrm{C} / \mathrm{min}$. The weight of each sample was $5.0 \mathrm{mg}$.

The rate of water absorption of the sample was determined according to the ASTM_D570 standard. The test specimens for homogeneous plastics measuring 60 by 60 by $1 \mathrm{~mm}$ were prepared directly by hot press molding. The specimens were firstly dried in an oven for $24 \mathrm{~h}$ at $50^{\circ} \mathrm{C}$, cooled in a desiccator, and immediately weighed to the nearest $0.001 \mathrm{~g}$, before being placed in a container of distilled water maintained at a temperature of $23+1{ }^{\circ} \mathrm{C}$, resting on edge while entirely immersed. After $24 \mathrm{~h}$, the specimens were removed from the water one at a time, all water was wiped off the surfaces of the specimens with a dry cloth, and the specimens were weighed to the nearest 0.001 g immediately.

\subsection{Procedures}

\subsubsection{Synthesis of PA6 porous microspheres}

The procedure for preparing PA6 porous microspheres used three steps: First, we dissolved the PA6 pellets and PVP-K30 powder with concentrations of 
12.5 and $8.0 \mathrm{wt} \%$, respectively, in acetic acid under heating until a transparent homogeneous solution formed. Second, we added ethanol as the poor solvent 2 times the amount of acetic acid to the acetic acid solution with vigorous stirring until the PA6 was precipitated and dispersed as white particles in the mixture. Third, we filtered and washed the precipitate with ethanol and water until the acetic acid and PVP were removed. The resulting white powder was dried in an oven at $90^{\circ} \mathrm{C}$ for direct testing and used without additional screening.

\subsubsection{Synthesis of $\mathrm{PA6} / \mathrm{SiO}_{2}$ composites}

To prepare the $\mathrm{PA} 6 / \mathrm{SiO}_{2}$ composite, the prepared PA6 porous microspheres were firstly added and dispersed in a mixed solvent of ethanol and ammonia water $\left(\mathrm{NH}_{3} \cdot \mathrm{H}_{2} \mathrm{O}\right)$ under stirring. Then TEOS was added and heated to $40^{\circ} \mathrm{C}$ for $20 \mathrm{~h}$ with vigorous stirring to finish the hydrolysis-condensation reaction. The resulting white powder was dried in an oven at $90^{\circ} \mathrm{C}$ for direct testing without any other screening. The ethanol and PVP were recycled for further use.

\section{Results and discussion}

The preparation of $\mathrm{PA} 6 / \mathrm{SiO}_{2}$ composite microspheres was conducted by firstly preparing porous PA6 microspheres using a modified phase-separation process and then generating nanoscale $\mathrm{SiO}_{2}$ within the PA6 porous microsphere framework, using a typical sol-gel technique. The preparation of the PA6 porous microspheres was conducted by a modified dissolution precipitation method. Compared to other methods in the literature, the advantages of this preparation process can be summarized as follows: 1) A low-boiling-point solvent could be applied as the good solvent, making the obtained powder easily dried. 2) A mild reaction temperature without pressure was applied during the preparation process, thus effectively preventing the polymer from decomposition at high temperatures. 3) The preparation process does not depend on the grade of the raw materials. The porous microspheres could be obtained by using different sources of raw materials. In addition, the powder can perform amplification in the 50 L reactor. 4) By controlling the experimental conditions, we can obtain PA6 microspheres with controlled sizes and bulk densities.

Figure 2a-2c depict SEM images of the PA6 porous microspheres. As shown, the porous microspheres with average particle sizes of $50 \mu \mathrm{m}$ exhibit spherical coil structures, intertwined by a ball of micrometer-scale lines with diameters of $1-3 \mu \mathrm{m}$, with many random pores of $1-5 \mu \mathrm{m}$ on the surface. To examine the inside structure, the porous microspheres were cut with high energy gallium focused ion beam (FIB) and characterized by a high resolution microscope which integrated in a 3-in-1 multibeam ion microscope. The cross-section shows many through-holes inside the porous microsphere, which is similar to the surface pore structure. Obviously, the pores of the porous microspheres are interlinked (Figure $2 \mathrm{~g}$ ). The porous microspheres can be directly used for the in situ growth of $\mathrm{SiO}_{2}$ without further processing. It is gratifying that the $\mathrm{SiO}_{2}$ grows selectively inside the PA6 porous microspheres, rather than in the outside solution. This high degree of selectivity may relate to the intermolecular hydrogen-bonding interactions between the hydroxyl groups on the surface of the $\mathrm{SiO}_{2}$ and the amide groups of the PA6 chains. Because of this, the silica firstly selected to be deposited around the surface of nylon 6 micrometer-scale lines. In addition, due to the self intermolecular interaction of silica particles the generated $\mathrm{SiO}_{2}$ accumulates continuously in the same place. This eventually results in the gradual filling of the surface and internal pores of the porous microspheres, which are intertwined by the micrometer-scale lines. However, when the pores of nylon 6 microspheres are gradually filled with silica, little space was left for the generation of $\mathrm{SiO}_{2}$ in the inner of the microsphere, while $\mathrm{SiO}_{2}$ tends to grow on the surface of microspheres.

After the in situ growth of $\mathrm{SiO}_{2}$, the surface porous structure is completely filled with $\mathrm{SiO}_{2}$, although the particle size of the composite microspheres does not obviously change as shown in Figure $2 \mathrm{~d}-2 \mathrm{f}$. Scanning electron microscope energy dispersion spectra of $\mathrm{PA} 6 / \mathrm{SiO}_{2}$ composite confirmed the existence of $\mathrm{SiO}_{2}$ (Figure 2i). The cross-section obtained after FIB cutting shows that most of the pores within the microsphere are filled effectively. Importantly, the SEM images of the PA6/ $\mathrm{SiO}_{2}$ composite microspheres are clearer (Figure $2 \mathrm{~h}$ ) than those of the PA6 microspheres, indicating that the electrical conductive properties of the composite microspheres are significantly improved compared with that of pure PA6. It is reasonable to believe that good electrical conductivity can effectively reduce the electrostatic adsorption capacity of powder in the powder-laying device during SLS processing. 


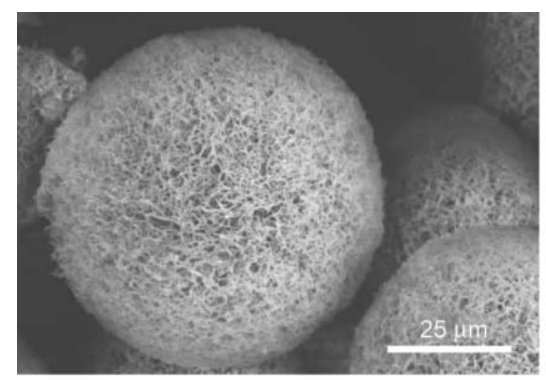

a)

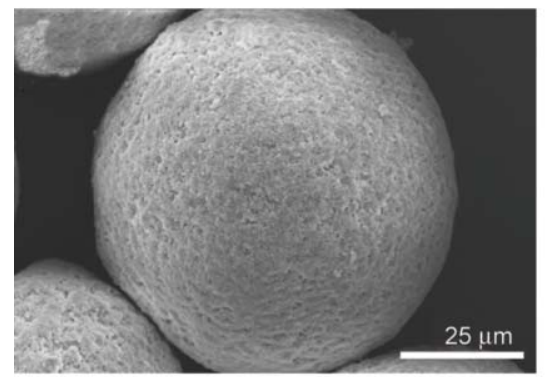

d)

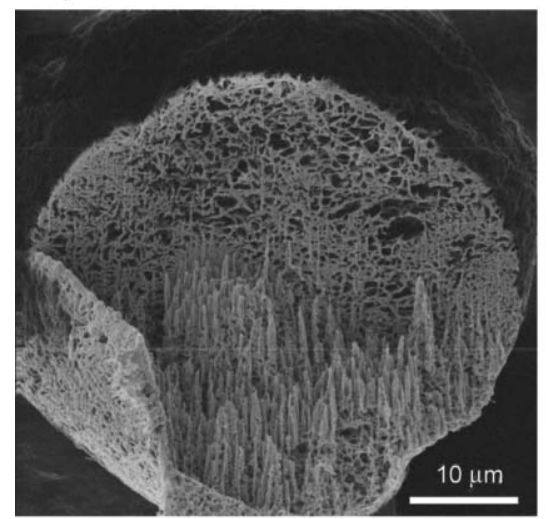

g)

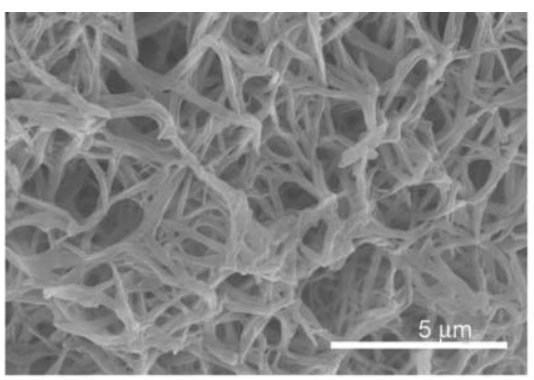

b)

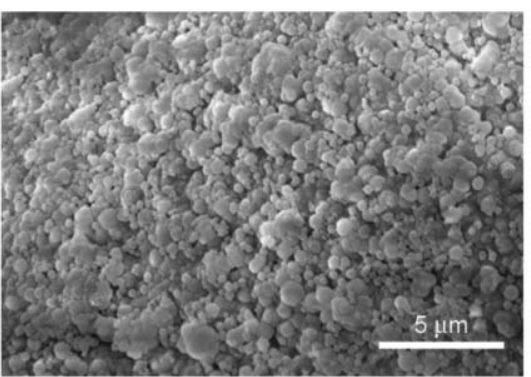

e)

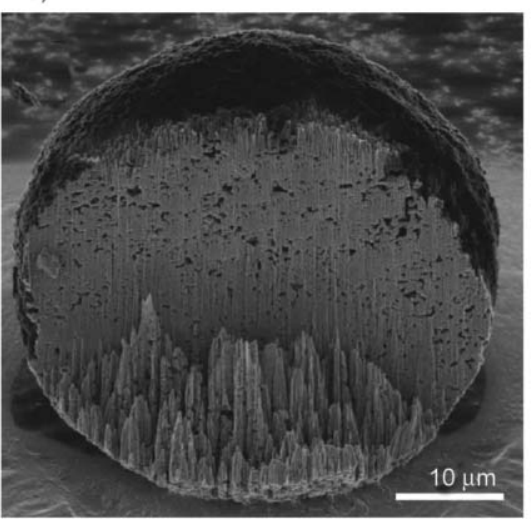

h)

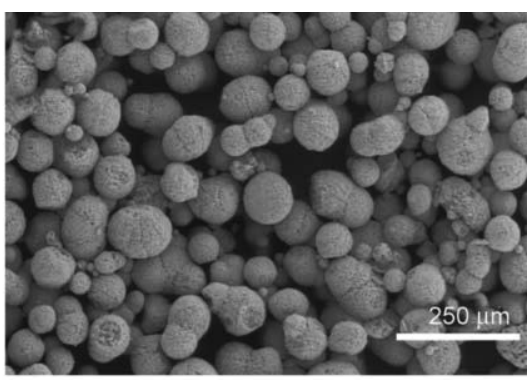

c)

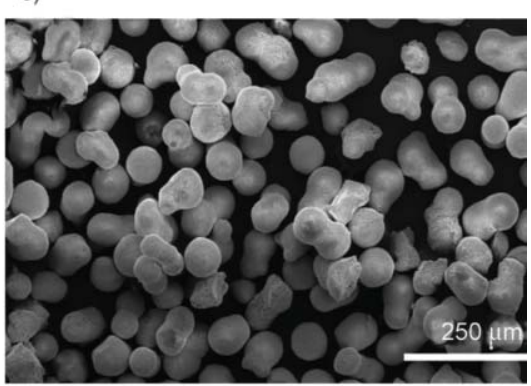

f)

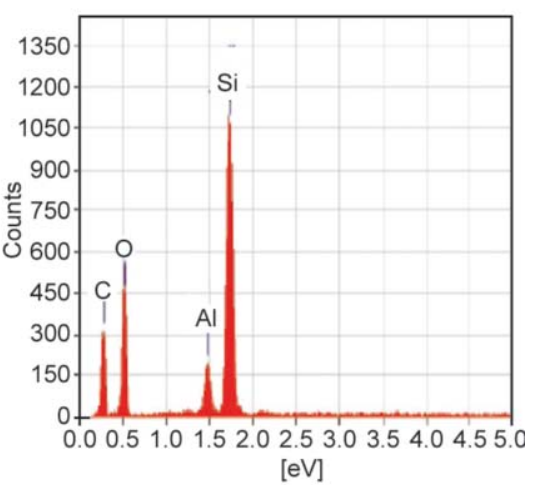

$[\mathrm{eV}]$

i)

Figure 2. a-c) SEM photographs of PA6 porous microspheres at different magnifications; d-f) $\mathrm{SEM}$ photographs of $\mathrm{PA} 6 / \mathrm{SiO}_{2}$ composite microspheres at different magnifications; g) cross-sectional image of PA6 porous microsphere; $h$ ) crosssectional image of $\mathrm{PA} 6 / \mathrm{SiO}_{2}$ composite microsphere; i) scanning electron microscope energy dispersion spectra of $\mathrm{PA} 6 / \mathrm{SiO}_{2}$ composite carried

The properties of the PA6 porous microspheres were important for the construction of the $\mathrm{PA} 6 / \mathrm{SiO}_{2}$ composites. These properties are strongly dependent on the preparation conditions. Among these conditions, the PVP concentration is especially crucial as PVP acts as a dispersant in preparation. When no PVP is used, only random powder can be obtained. The size and diameter of the porous microspheres is significantly changed when different weight ratios of PVP are introduced. With the increase of PVP content to 4,8 , and $12 \mathrm{wt} \%$, the diameter of the microspheres decreases to 75,50 , and $18 \mu \mathrm{m}$, respectively, while the pore volume decreases to $9.84,6.83$, and $5.70 \mathrm{~mL} / \mathrm{g}$, respectively, as shown in Figure 3 and Table 1.

The PA6 porous microspheres have large porosities and specific surface areas with large load capacities, suitable for application in the field of painting.
However, the bulk density of the powder is low and the mobility is poor, so such microspheres are unsuitable for SLS. In order to improve the sintering properties of the powder, the porous PA6 spheres of $50 \mu \mathrm{m}$ in particle size were used as templates, and $\mathrm{SiO}_{2}$ at weight ratios of $5,27,32$, and $65 \%$ is introduced to the porous microspheres by in situ hydrolysis. As the $\mathrm{SiO}_{2}$ content increases, the pore volume and porosity of the composite microspheres decrease significantly, while the bulk density and flowability are greatly improved, as shown in Table 2 and Figure 4.

The thermal stability of materials is characterized by TGA, in which the weight loss is monitored as a function of the temperature. TGA measurements of neat PA6 and its composites with varying amounts of $\mathrm{SiO}_{2}$ were performed, and the $\mathrm{SiO}_{2}$ content determined in each composite microsphere from TGA is 


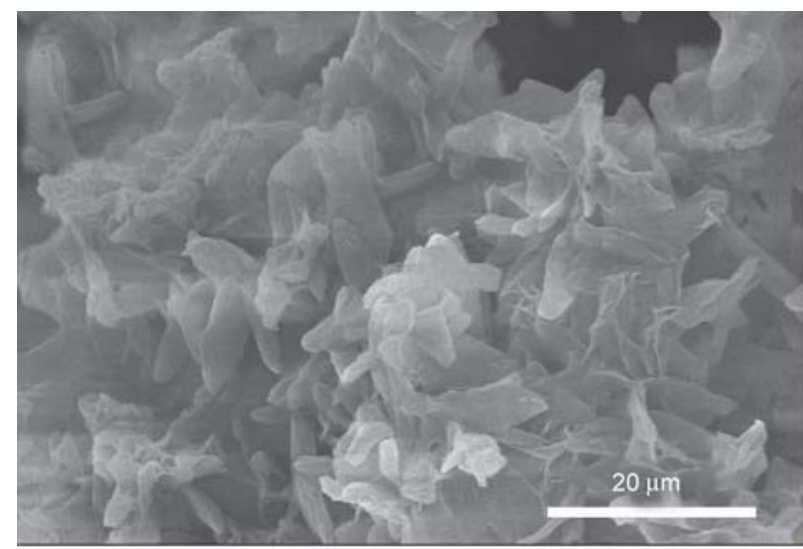

a)

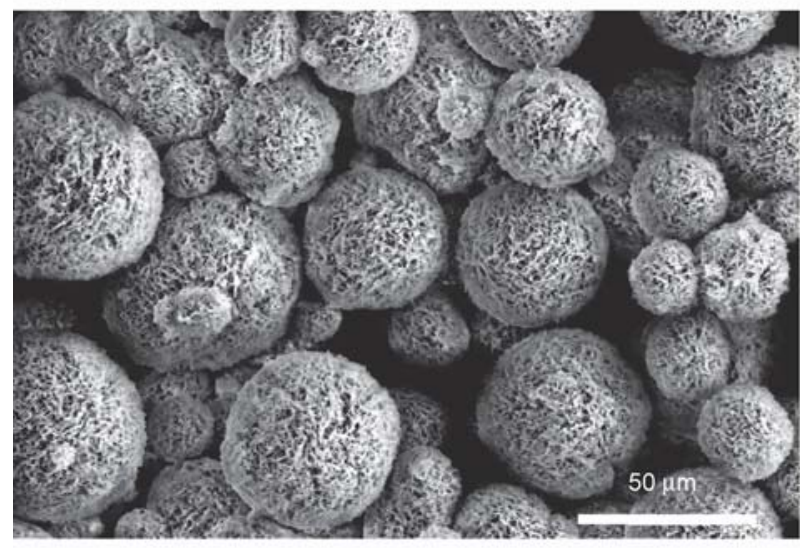

c)

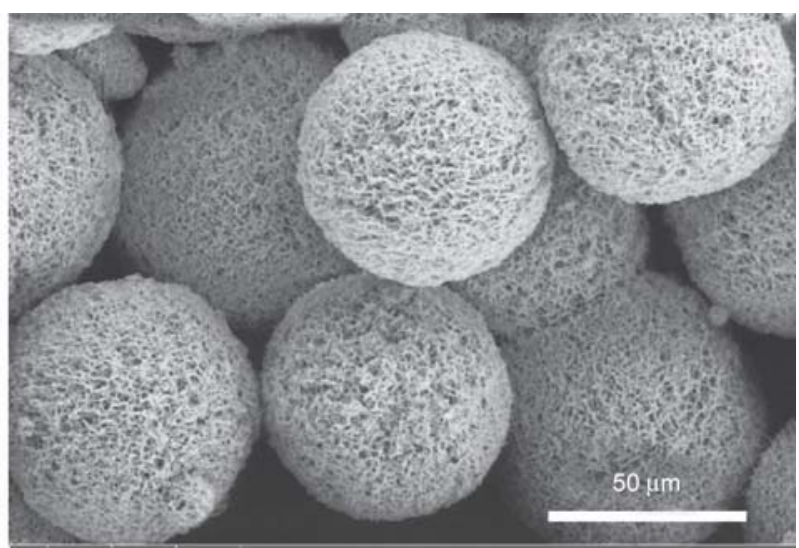

b)

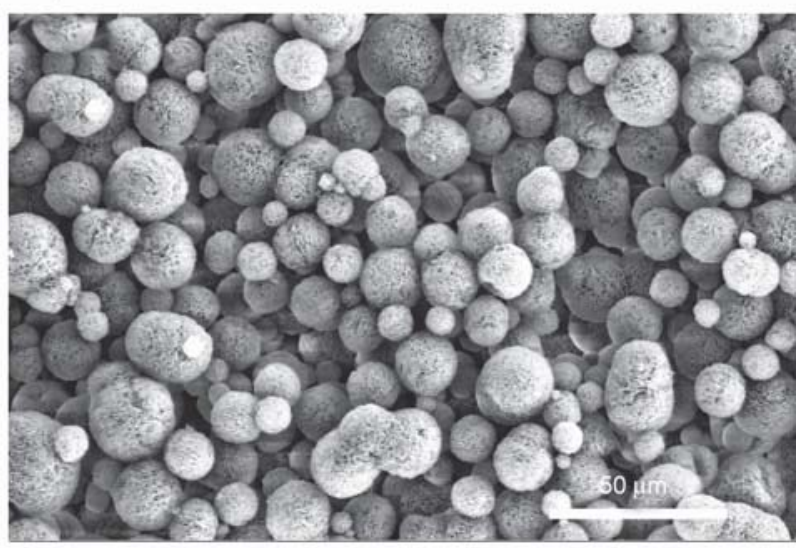

d)

Figure 3. SEM photographs of PA6 porous microspheres precipitated from solution with PVP added at concentrations of a) $0 \mathrm{wt} \%$; b) $4 \mathrm{wt} \%$; c) $8 \mathrm{wt} \%$; d) $12 \mathrm{wt} \%$

Table 1. Conditions of phase separation procedures and the resulting particle sizes, bulk densities, and pore properties

\begin{tabular}{|c|c|c|c|c|c|c|}
\hline Powder No. & $\begin{array}{c}\text { PVP } \\
{[\mathbf{w t} \mathbf{\%}]}\end{array}$ & $\begin{array}{c}\text { Diameter, } \boldsymbol{d}(\mathbf{0 . 5}) \\
{[\boldsymbol{\mu \mathbf { m } ]}}\end{array}$ & $\begin{array}{c}\text { Bulk density } \\
{\left[\mathbf{g} / \mathbf{c m}^{\mathbf{3}}\right]}\end{array}$ & $\begin{array}{c}\text { Pore volume } \\
{[\mathbf{m} \mathbf{L} / \mathbf{g}]}\end{array}$ & $\begin{array}{c}\text { Mean diameter of pore } \\
{[\boldsymbol{\mu} \mathbf{m}]}\end{array}$ & $\begin{array}{c}\text { Porosity } \\
{[\mathbf{\%}]}\end{array}$ \\
\hline 1 & 0 & $<10.0$ & - & - & - & - \\
\hline 2 & 4 & 75.0 & 0.12 & 9.84 & 1.23 & 85.1 \\
\hline 3 & 8 & 50.0 & 0.19 & 6.83 & 1.53 & 79.9 \\
\hline 4 & 12 & 18.0 & 0.23 & 5.70 & 0.99 & 77.1 \\
\hline
\end{tabular}

Table 2. Properties of $\mathrm{PA} 6 / \mathrm{SiO}_{2}$ composite microspheres with different concentrations of $\mathrm{SiO}_{2}$

\begin{tabular}{|c|c|c|c|c|c|}
\hline Powder No. & $\begin{array}{c}\mathbf{S i O}_{\mathbf{2}} \text {, calculated } \\
{[\mathbf{w t} / \mathbf{0}]}\end{array}$ & $\begin{array}{c}\text { Bulk density } \\
{\left[\mathbf{g} / \mathbf{c m}^{\mathbf{3}}\right]}\end{array}$ & $\begin{array}{c}\text { Pore volume } \\
{[\mathbf{m L} / \mathbf{g}]}\end{array}$ & $\begin{array}{c}\text { Mean diameter of pore } \\
{[\boldsymbol{\mu m}]}\end{array}$ & $\begin{array}{c}\text { Porosity } \\
{[\mathbf{\%}]}\end{array}$ \\
\hline 1 & 0 & 0.19 & 6.83 & 1.53 & 85.1 \\
\hline 2 & 5 & 0.21 & 5.96 & 1.45 & 81.5 \\
\hline 3 & 17 & 0.23 & 2.99 & 1.15 & 77.5 \\
\hline 4 & 32 & 0.29 & 2.07 & 0.44 & 67.8 \\
\hline 5 & 65 & 0.42 & 1.72 & 0.39 & 51.9 \\
\hline
\end{tabular}

The weight content of $\mathrm{SiO}_{2}$ was calculated by the weight of feeding TEOS and the conversion rate of $\mathrm{SiO}_{2}$ synthesized by TEOS.

reported in Table 3 and Figure 5, along with the theoretical $\mathrm{SiO}_{2}$ content and the temperatures at which $10,50 \%$, and the fastest weight losses occur. The thermal degradation temperatures of the PA6 nanocomposites are decreased significantly compared to that for neat PA6, suggesting that the thermal stability of the nanocomposites is decreased compared to that of neat PA6. Compared with the pure PA6 powder, $\mathrm{SiO}_{2}$ in PA6 nanocomposites cannot be decomposed under the experimental temperature. Thus, the 


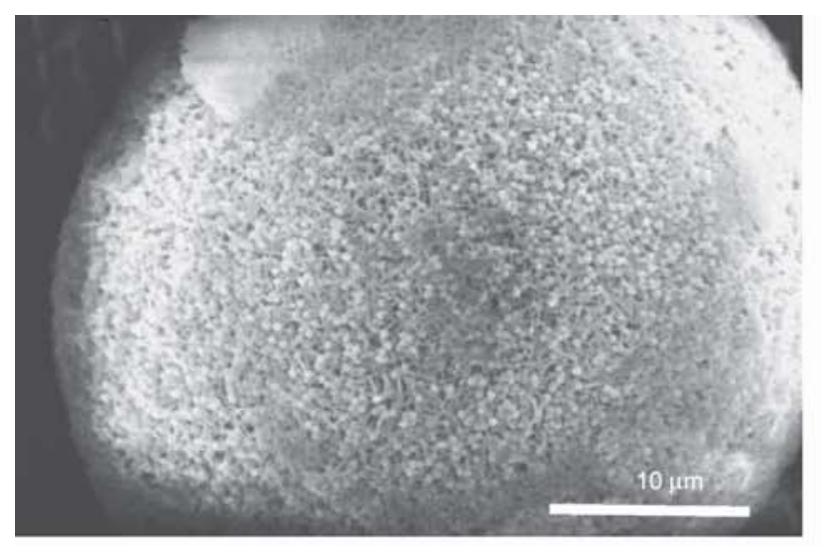

a)

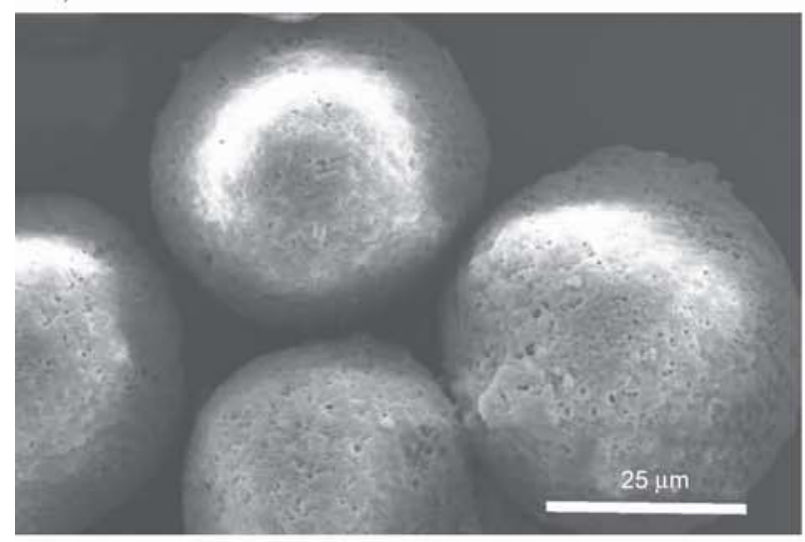

c)

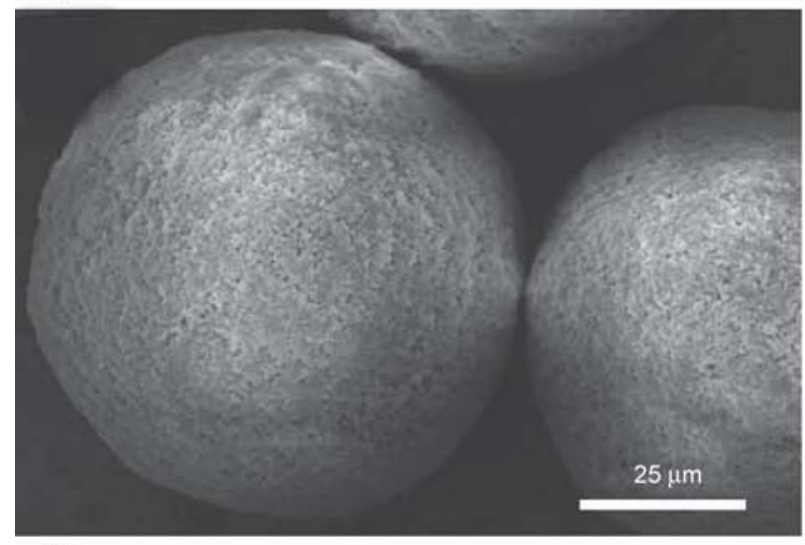

e)

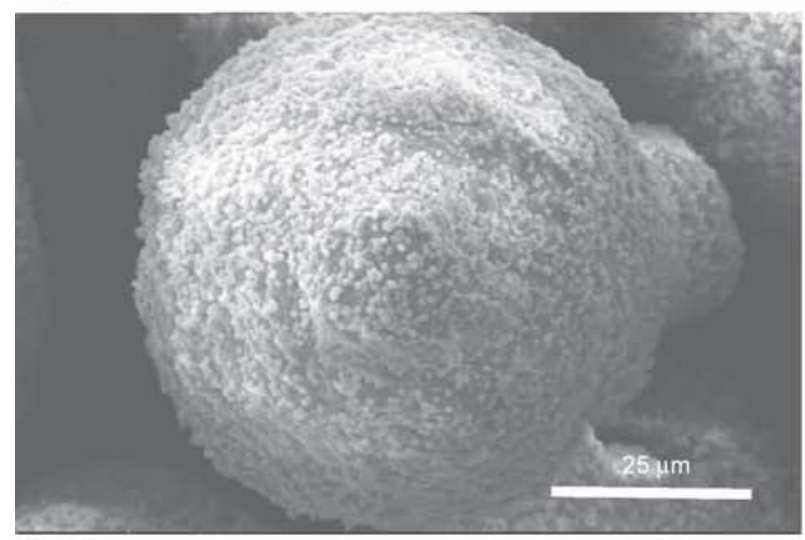

g)

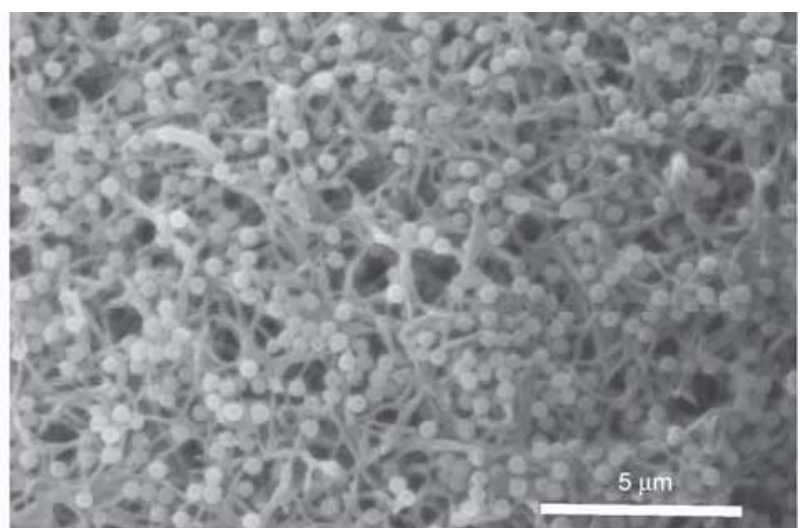

b)

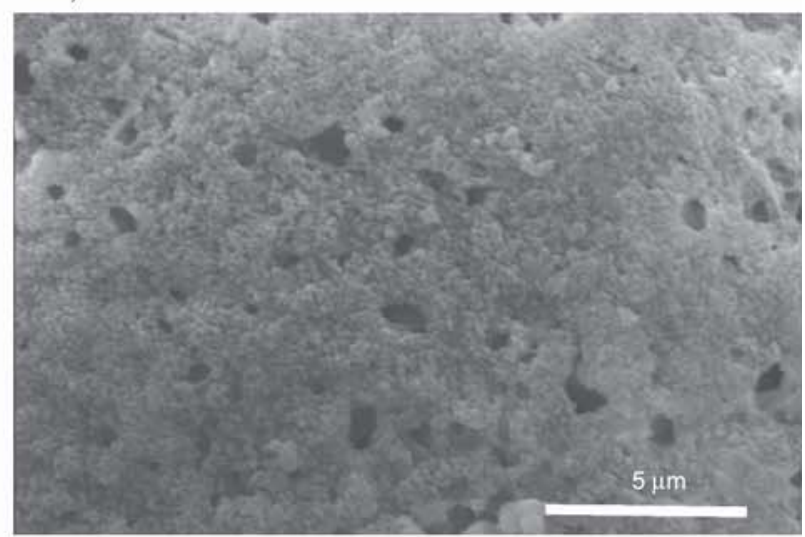

d)

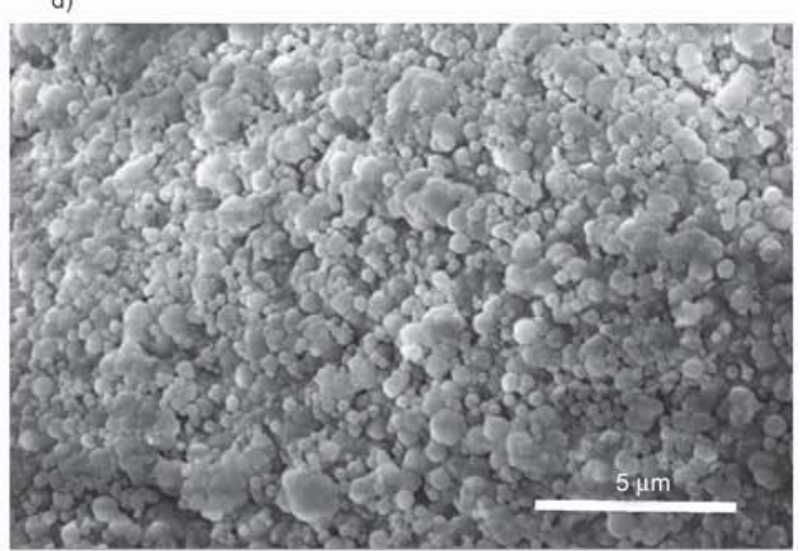

f)

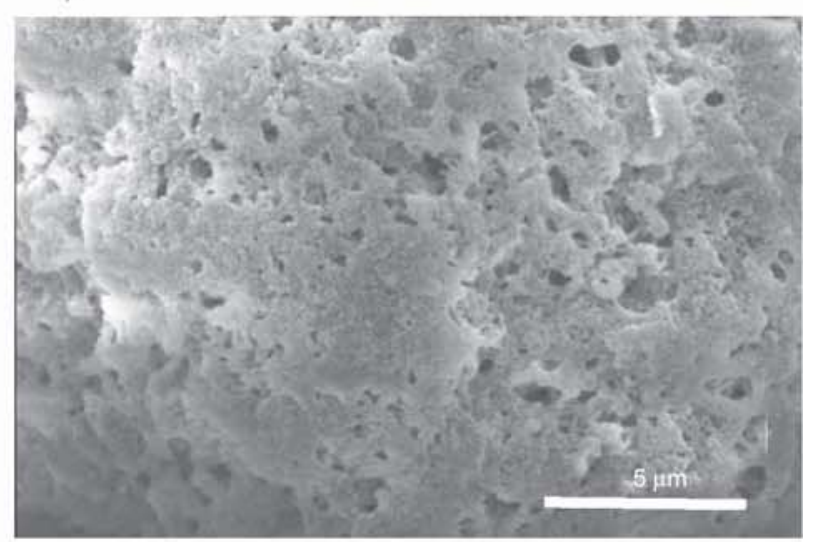

h)

Figure 4. $\mathrm{SEM}$ photographs of $\mathrm{PA} 6 / \mathrm{SiO}_{2}$ composite microspheres with $\mathrm{SiO}_{2}$ prepared at concentrations of a-b) $5 \mathrm{wt} \%$ when the growth temperature is $30^{\circ} \mathrm{C}$; c-d) $17 \mathrm{wt} \%$ when the growth temperature is $30^{\circ} \mathrm{C}$; e-f) $32 \mathrm{wt} \%$ when the growth temperature is $\left.70^{\circ} \mathrm{C} ; \mathrm{g}-\mathrm{h}\right) 65 \mathrm{wt} \%$ when the growth temperature is $80^{\circ} \mathrm{C}$ 
Table 3. The thermal stability of PA6 and its composites containing 5-65\% $\mathrm{SiO}_{2}$, characterized by TGA

\begin{tabular}{|c|c|c|c|c|c|}
\hline $\begin{array}{c}\text { Powder } \\
\text { No. }\end{array}$ & $\begin{array}{c}\mathbf{S i O}_{2}, \\
\text { calulated } \\
{[\mathbf{w t} \%]}\end{array}$ & $\begin{array}{c}\mathrm{SiO}_{\mathbf{2}}, \\
\mathbf{T G A} \\
{[\mathbf{w t} \%]}\end{array}$ & $\begin{array}{c}\boldsymbol{T}_{\mathbf{1 0}} \% \\
{\left[{ }^{\circ} \mathbf{C}\right]}\end{array}$ & $\begin{array}{c}\boldsymbol{T}_{\mathbf{5 0}} \% \\
{\left[{ }^{\circ} \mathbf{C}\right]}\end{array}$ & $\begin{array}{c}\boldsymbol{T}_{\mathbf{f}} \\
{\left[{ }^{\circ} \mathbf{C}\right]}\end{array}$ \\
\hline Pellets & 0.0 & 0.0 & 408.2 & 443.5 & 451.7 \\
\hline 1 & 0.0 & 0.0 & 403.1 & 441.2 & 449.1 \\
\hline 2 & 5.0 & 4.9 & 397.6 & 431.1 & 438.9 \\
\hline 3 & 17.0 & 16.7 & 396.0 & 428.6 & 433.8 \\
\hline 4 & 32.0 & 30.5 & 374.8 & 417.1 & 438.2 \\
\hline 5 & 65.0 & 63.8 & 367.1 & 405.8 & 410.8 \\
\hline
\end{tabular}

$T_{10 \%}$ and $T_{50 \%}$ indicate the temperatures at which 10 and $50 \%$ weight loss of PA6 occur, respectively. $T_{\mathrm{f}}$ indicates the temperature at which the fastest weight loss of PA6 occurs.

TGA curve of composite powder shows a plateau at a certain weight percentage. The weight loss before this plateau represents the content of PA6 in PA6/ $\mathrm{SiO}_{2}$ composite. The actual $\mathrm{SiO}_{2}$ content, can be determined by weight percentage at this plateau represents, which appears only slightly lower than the theoretical

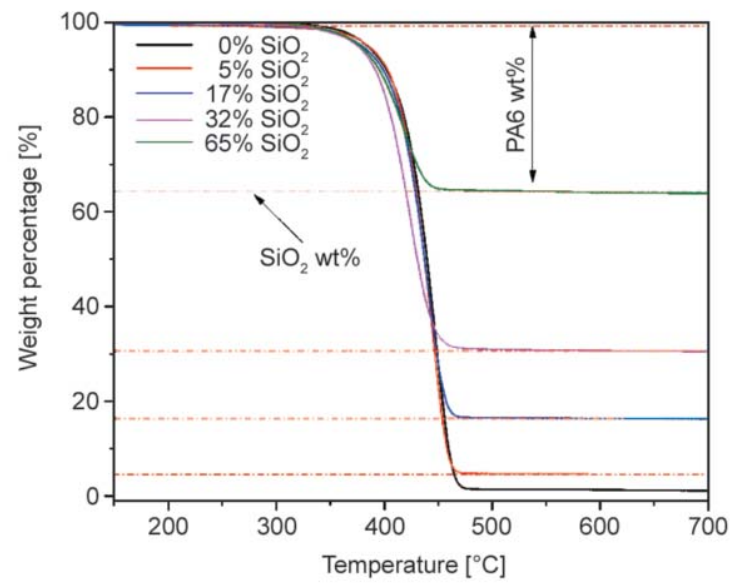

Figure 5. TGA thermogram comparison of raw PA6 pellets and the experimentally prepared $\mathrm{PA} 6 / \mathrm{SiO}_{2}$ composite microspheres with $\mathrm{SiO}_{2}$ prepared at concentrations of 5, 17, 32 and $65 \mathrm{wt} \%$ amount given in Table 3. This shows that the sol-gel reaction is almost complete in all cases. The decreases in the thermal stability of the $\mathrm{PA} 6 / \mathrm{SiO}_{2}$ composites is consistent with other reports [33], in which the thermal decomposition temperature reaches the maximum value as the $\mathrm{SiO}_{2}$ content reaches $\sim 3 \mathrm{wt} \%$, probably because of strong secondary interactions between $\mathrm{PA} 6$ chains and $\mathrm{SiO}_{2}$. When the $\mathrm{SiO}_{2}$ content is increased more, the thermal conductivity of the large amount of inorganic powder renders the complex more easily decomposed.

During SLS processing, the larger sintering window can ensure better controllability of the powder. Accordingly, we studied the thermal and crystallization properties of the $\mathrm{PA} 6 / \mathrm{SiO}_{2}$ composite microspheres by DSC. As shown in Figure 6 and Table 4, pure PA6 pellets have melting and crystallization peaks at 222.5

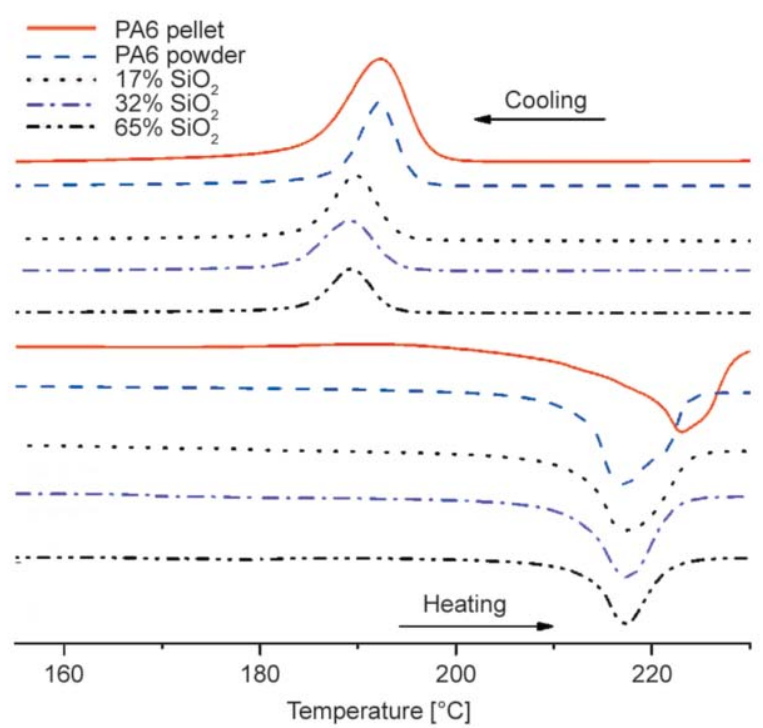

Figure 6. DSC thermogram comparison of raw PA6 pellets and the experimentally prepared $\mathrm{PA} 6 / \mathrm{SiO}_{2}$ composite microspheres with $\mathrm{SiO}_{2}$ prepared at concentrations of $0,17,32$ and $65 \mathrm{wt} \%$

Table 4. Melting and crystallization characteristics for raw PA6 pellets and prepared PA6 powder

\begin{tabular}{|c|c|c|c|c|c|c|c|c|}
\hline $\begin{array}{c}\text { Powder } \\
\text { No. }\end{array}$ & $\begin{array}{c}\mathbf{S i O}_{2,} \mathbf{~ T G A} \\
{[\mathbf{w t} \% \mathbf{0}]}\end{array}$ & $\begin{array}{c}\text { Peak } \boldsymbol{T}_{\mathbf{m}} \\
{\left[{ }^{\circ} \mathbf{C}\right]}\end{array}$ & $\begin{array}{c}\text { Onset of } \boldsymbol{T}_{\mathbf{m}} \\
{\left[{ }^{\circ} \mathbf{C}\right]}\end{array}$ & $\begin{array}{c}\text { Melting enthalpy, } \\
\mathbf{\Delta} \boldsymbol{H}_{\mathbf{f}}{ }^{\mathbf{a}} \\
{[\mathbf{J} / \mathbf{g}]}\end{array}$ & $\begin{array}{c}\text { Peak } \boldsymbol{T}_{\mathbf{c}} \\
{\left[{ }^{\circ} \mathbf{C}\right]}\end{array}$ & $\begin{array}{c}\text { Onset of } \boldsymbol{T}_{\mathbf{c}} \\
{\left[{ }^{\circ} \mathbf{C}\right]}\end{array}$ & Crystallinity & $\begin{array}{c}\text { Sintering window } \\
{\left[{ }^{\circ} \mathbf{C}\right]}\end{array}$ \\
\hline Pellets & 0.0 & 222.5 & 217.3 & -65.5 & 192.9 & 197.5 & 34.8 & - \\
\hline 1 & 0.0 & 216.5 & 212.9 & -94.6 & 192.6 & 195.7 & 50.3 & 17.2 \\
\hline 2 & 4.9 & 216.7 & 212.7 & -75.9 & 190.8 & 194.4 & 42.5 & 18.3 \\
\hline 3 & 16.7 & 216.9 & 212.6 & -67.4 & 190.2 & 193.9 & 43.2 & 18.7 \\
\hline 4 & 30.5 & 217.1 & 212.3 & -62.8 & 189.5 & 193.6 & 49.1 & 18.7 \\
\hline 5 & 63.8 & 216.9 & 213.2 & -37.8 & 189.6 & 193.3 & 57.4 & 19.9 \\
\hline
\end{tabular}

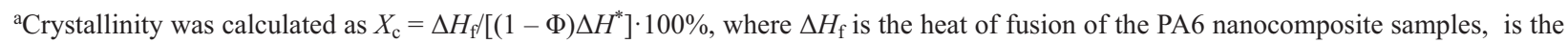
heat of fusion of $100 \%$ crystalline PA6, taken as $188 \mathrm{~J} / \mathrm{g}$, and $\Phi$ is the weight fraction of $\mathrm{SiO}_{2}$ in the composite sample.

${ }^{\text {b}} T$ he 'sintering window' for SLS processing was calculated as $\Delta T=\left(T_{\mathrm{m}}-T_{\mathrm{c}}\right)$. 
and $192.9^{\circ} \mathrm{C}$, with melting enthalpy and crystallinity of $-65.5 \mathrm{~J} / \mathrm{g}$ and $34.8 \%$, respectively. In the powder preparation process, the arrangement of the molecular chains is more regular, which resulted in a higher melting enthalpy and crystallinity of $-94.6 \mathrm{~J} / \mathrm{g}$ and $50.3 \%$, respectively. On the other hand, because pure PA6 recrystallized at a lower temperature, the size of the crystal decreases relatively in the powder preparation process. Thus, the melting temperature of PA6 powder is lower than the pellets and the crystallization temperature remains constant.

After the introduction of $\mathrm{SiO}_{2}, \mathrm{SiO}_{2}$ was polymerized on the template of the PA6 porous microsphere, with no influence on the PA6 matrix structure. Thus, when the content of $\mathrm{SiO}_{2}$ is increased in the range of $27-65 \%$, the melting temperature is slightly increased from 216.5 to $217.1{ }^{\circ} \mathrm{C}$ when $\mathrm{SiO}_{2}$ content is $32 \%$. More importantly, the introduction of $\mathrm{SiO}_{2}$ have significant effect on the PA6 crystallization process. On the one hand, the introduction of inorganic powders may promote the crystal nucleation process thus lead a more rapid crystallization process and higher crystallization temperature. On the other hand, the introduction of inorganic powders may increase the overall thermal conductivity of composite powders, thus hindering the crystallization process and reducing the crystallization temperature on the contrary [34]. Because of the combined effect of these two aspects, the crystallization temperature of composite powders decreases from 192.6 to $189.5^{\circ} \mathrm{C}$ with the increase of $\mathrm{SiO}_{2}$ content, while the crystallinity calculated from the melting enthalpy decreased first and then increased. More importantly, the sintering window which represent the gap between the onset of melting and crystallization temperature are increased to $18.3,18.7,18.7,19.9^{\circ} \mathrm{C}$, respectively. Therefore, the composite powder has a wider sintering window than the PA6 pure pellet does. The material prepared by the dissolution precipitation method first forms a porous powder with a high melting enthalpy, and then the sintering window is increased by the method of in situ introduction of $\mathrm{SiO}_{2}$. The composite material prepared by our method has a wider sintering window, which permits improved controllability of the sintering process.

The water absorption rate of the PA6 powder is another important factor affecting the forming precision of sintered parts. Accordingly, the water absorption rates of the PA6 pellets, porous powder, and composite powders were tested. According to the test standard, the pellets and powders were first hotpressed into shells and then immersed in water for $24 \mathrm{~h}$; the water absorption rate was calculated according to the quality of the shells before and after water immersion. The pure PA6 powder and pellets have similar water absorption rates of 4.1 and $4.3 \%$ respectively. After the introduction of $\mathrm{SiO}_{2}$, the water absorption of the shell of the composite powder decreases obviously, and the water absorption rate continues to decrease as the $\mathrm{SiO}_{2}$ content increases. When the $\mathrm{SiO}_{2}$ content in the composite powder is $5,17,32$, and $65 \%$, the corresponding water absorption rate is $3.1,1.8,0.81$, and $0.35 \%$, respectively. The decrease of water absorption of the composite microspheres should be analyzed from the following two aspects, one is the hydrophilic amide groups in the PA6 polymer chain decrease significantly because the intermolecular hydrogen-bonding interactions between the hydroxyl groups on the surface of the $\mathrm{SiO}_{2}$ and the amide groups of the PA6 chains. The other is $\mathrm{SiO}_{2}$ inside the PA6 porous microspheres occupied most innerspace of composite microspheres, so there is no enough space for water molecules absorption.

\section{Conclusions}

In this study, a new kind of $\mathrm{PA} 6 / \mathrm{SiO}_{2}$ composite microsphere structure is designed and constructed by in situ generation of $\mathrm{SiO}_{2}$ within a PA6 porous microsphere framework, thus achieving good dispersion of many $\mathrm{SiO}_{2}$ particles in the PA6 matrix. The in situ preparation technology and the effect of the structure on the powder properties are investigated to obtain controllable properties of the composite microspheres by manipulating the preparation process. The bulk density, conductivity, and mobility of the composite powders were effectively improved by the introduction of $\mathrm{SiO}_{2}$. Simultaneously, the crystallinity of PA6 in the composite powder was improved, which decreased the crystallization temperature and broadened the sintering window. The filling of the PA6 matrix and the improvement of the degree of crystallization by the $\mathrm{SiO}_{2}$ decrease the water absorption of the composite material. This polymer-based composite material preparation technique may provide new ideas for adjusting the functionality of materials, as well as enabling low-cost and high-performance SLS technology with polymer powders prepared by this new technique. 


\section{Acknowledgements}

The authors would like to thank the National Natural Science Foundation of China (Project No. 51603212 and 51473175), and the Hangzhou City Economic and Technological Development Zone for financial support.

\section{References}

[1] Vaezi M., Seitz H., Yang S.: A review on 3D micro-additive manufacturing technologies. International Journal of Advanced Manufacturing Technology, 67, 17211754 (2013).

https://doi.org/10.1007/s00170-012-4605-2

[2] Kumar S.: Selective laser sintering: A qualitative and objective approach. Journal of the Minerals Metals and Materials Society, 55, 43-47 (2003).

https://doi.org/10.1007/s11837-003-0175-y

[3] Goodridge R. D., Tuck C. J., Hague R. J. M.: Laser sintering of polyamides and other polymers. Progress in Materials Science, 57, 229-267 (2012).

https://doi.org/10.1016/j.pmatsci.2011.04.001

[4] Kruth J. P., Wang X., Laoui T., Froyen L.: Lasers and materials in selective laser sintering. Assembly Automation, 23, 357-371 (2003).

https://doi.org/10.1108/01445150310698652

[5] Kenzari S., Bonina D., Dubois J. M., Fournée V.: Quasicrystal-polymer composites for selective laser sintering technology. Materials and Design, 35, 691-695 (2012). https://doi.org/10.1016/j.matdes.2011.10.032

[6] Zhu W., Yan C., Shi Y., Wen S., Han C., Cai C., Liu J., Shi Y.: Study on the selective laser sintering of a lowisotacticity polypropylene powder. Rapid Prototyping Journal, 22, 621-629 (2016).

https://doi.org/10.1108/rpj-02-2015-0014

[7] Zhu W., Yan C., Shi Y., Wen S., Liu J., Shi Y.: Investigation into mechanical and microstructural properties of polypropylene manufactured by selective laser sintering in comparison with injection molding counterparts. Materials and Design, 82, 37-45 (2015).

https://doi.org/10.1016/j.matdes.2015.05.043

[8] Yang J., Shi Y., Shen Q., Yan C.: Selective laser sintering of HIPS and investment casting technology. Journal of Materials Processing Technology, 209, 1901-1908 (2009).

https://doi.org/10.1016/j.jmatprotec.2008.04.056

[9] Schmid M., Amado A., Wegener K.: Materials perspective of polymers for additive manufacturing with selective laser sintering. Journal of Materials Research, 29, 1824-1832 (2014).

https://doi.org/10.1557/jmr.2014.138

[10] Lim B-S., Kim H-I., Kim D-S., Bang Y-K.: The effect of polyamide particles on the processibility of selective laser sintering. International Journal of Modern Physics B, 22, 1827-1832 (2008).

https://oi.org/10.1142/s0217979208047481
[11] Wang G., Wang P., Zhen Z., Zhang W., Ji J.: Preparation of PA12 microspheres with tunable morphology and size for use in SLS processing. Materials and Design, 87, 656-662 (2015).

https://doi.org/10.1016/j.matdes.2015.08.083

[12] Guo Y., Jiang K., Bourell D. L.: Preparation and laser sintering of limestone PA12 composite. Polymer Testing, 37, 210-215 (2014).

https://doi.org/10.1016/j.polymertesting.2014.06.002

[13] Mazzoli A., Moriconi G., Pauri M. G.: Characterization of an aluminum-filled polyamide powder for applications in selective laser sintering. Materials and Design, 28, 993-1000 (2007). https://doi.org/10.1016/j.matdes.2005.11.021

[14] Paggi R. A., Beal V. E., Salmoria G. V.: Process optimization for PA12/MWCNT nanocomposite manufacturing by selective laser sintering. The International Journal of Advanced Manufacturing Technology, 66, 19771985 (2012). https://doi.org/10.1007/s00170-012-4474-8

[15] Yan C., Hao L., Xu L., Shi Y.: Preparation, characterisation and processing of carbon fibre/polyamide-12 composites for selective laser sintering. Composites Science and Technology, 71, 1834-1841 (2011).

https://doi.org/10.1016/j.compscitech.2011.08.013

[16] Yan C., Shi Y., Yang J., Liu J.: Preparation and selective laser sintering of nylon-12 coated metal powders and post processing. Journal of Materials Processing Technology, 209, 5785-5792 (2009).

https://doi.org/10.1016/j.jmatprotec.2009.06.010

[17] Bassoli E., Gatto A., Iuliano L.: Joining mechanisms and mechanical properties of PA composites obtained by selective laser sintering. Rapid Prototyping Journal, 18, 100-108 (2012).

https://doi.org/10.1108/13552541211212087

[18] Wudy K., Drummer D., Kühnlein F., Drexler M.: Influence of degradation behavior of polyamide 12 powders in laser sintering process on produced parts. AIP Conference Proceedings, 1593, 691-695 (2014). https://doi.org/10.1063/1.4873873

[19] Jones N. A., Cooper S. J., Atkins E. D. T., Hill M. J., Franco L.: Temperature-induced changes in chain-folded lamellar crystals of aliphatic polyamides. Investigation of nylons 2 6, 2 8, 2 10, and 2 12. Journal of Polymer Science Part B-Polymer Physics, 35, 675-688 (1997).

https://doi.org/10.1002/(sici)10990488(199703)35:4<675::aid-polb14>3.0.co;2-d

[20] Jones N. A., Atkins E. D. T., Hill M. J., Cooper S. J., Franco L.: Chain-folded lamellar crystals of aliphatic polyamides. Investigation of nylons 4 8, 4 10, 4 12, 6 10, 6 12, 618 and 8 12. Polymer, 38, 2689-2699 (1997). https://doi.org/10.1016/s0032-3861(97)85603-0

[21] Fornes T. D., Paul D. R.: Structure and properties of nanocomposites based on nylon-11 and -12 compared with those based on nylon-6. Macromolecules, 37, 76987709 (2004).

https://doi.org/10.1021/ma048757o 
[22] Hou W-H., Lobuglio T. M.: A new technique for preparing monodisperse polymer particles. II. Phase separation mechanisms. Journal of Applied Polymer Science, 54, 1363-1369 (1994). https://doi.org/10.1002/app.1994.070540918

[23] Li H., Wu Y., Sato H., Kong L., Zhang C., Huang K., Tao D., Chen J., Liu X., Zhao Y., Xu Y., Wu J., Ozaki Y.: A new facile method for preparation of nylon-6 with high crystallinity and special morphology. Macromolecules, 42, 1175-1179 (2009).

https://doi.org/10.1021/ma8019333

[24] Zhao X., Xia H., Fu X., Duan J., Yang G.: Preparation of polyamide- 6 submicrometer-sized spheres by in situ polymerization. Macromolecular Rapid Communications, 36, 1994-1999 (2015).

https://doi.org/10.1002/marc.201500358

[25] Pei A., Liu A., Xie T., Yang G.: A new strategy for the preparation of polyamide- 6 microspheres with designed morphology. Macromolecules, 39, 7801-7804 (2006). https://doi.org/10.1021/ma0619051

[26] Miri V., Persyn O., Lefebvre J-M., Seguela R.: Effect of water absorption on the plastic deformation behavior of nylon 6. European Polymer Journal, 45, 757-762 (2009). https://doi.org/10.1016/j.eurpolymj.2008.12.008

[27] Okada A., Usuki A.: Twenty years of polymer-clay nanocomposites. Macromolecular Materials and Engineering, 291, 1449-1476 (2006).

https://doi.org/10.1002/mame.200600260

[28] Dougnac V. N., Peoples B. C., Quijada R.: The effect of nanospheres on the permeability of $\mathrm{PA} 6 / \mathrm{SiO}_{2}$ nanocomposites. Polymer International, 60, 1600-1606 (2011). https://doi.org/10.1002/pi.3125
[29] Deák T., Czigány T., Tamás P., Németh C.: Enhancement of interfacial properties of basalt fiber reinforced nylon 6 matrix composites with silane coupling agents. Express Polymer Letters, 4, 590-598 (2010). https://doi.org/10.3144/expresspolymlett.2010.74

[30] Tadanaga K., Iwashita K., Minami T., Tohge N.: Coating and water permeation properties of $\mathrm{SiO}_{2}$ thin films prepared by the sol-gel method on nylon-6 substrates. Journal of Sol-Gel Science and Technology, 6, 107-111 (1996). https://doi.org/10.1007/bf00402593

[31] Li Y., Yu J., Guo Z-X.: The influence of silane treatment on nylon 6/nano- $\mathrm{SiO}_{2}$ in situ polymerization. Journal of Applied Polymer Science, 84, 827-834 (2002). https://doi.org/10.1002/app.10349

[32] Xu X., Li B., Lu H., Zhang Z., Wang H.: The effect of the interface structure of different surface-modified nano- $\mathrm{SiO}_{2}$ on the mechanical properties of nylon 66 composites. Journal of Applied Polymer Science, 107, 2007-2014 (2008). https://doi.org/10.1002/app.27325

[33] Rafique F. Z., Vasanthan N.: Crystallization, crystal structure, and isothermal melt crystallization kinetics of novel polyamide $6 / \mathrm{SiO}_{2}$ nanocomposites prepared using the sol-gel technique. Journal of Physical Chemistry B, 118, 9486-9495 (2014). https://doi.org/10.1021/jp505046v

[34] Miri V., Elkoun S., Peurton F., Vanmansart C., Lefebvre J-M., Krawczak P., Seguela R.: Crystallization kinetics and crystal structure of nylon 6-clay nanocomposites: Combined effects of thermomechanical history, clay content, and cooling conditions. Macromolecules, 41, 9234 9244 (2008). https://doi.org/10.1021/ma801804y 